\title{
MAGNESIUM PARTITION STUDIES IN GRAVES' DISEASE AND IN CLINICAL AND EXPERIMENTAL HYPOTHYROIDISM
}

\author{
By LOUIS J. SOFFER, CLARENCE COHN,1 EDWARD B. GROSSMAN, \\ MILDRED JACOBS, AND HARRY SOBOTKA \\ (From the Medical Service of Dr. George Baehr and the Chemical Laboratory \\ of The Mount Sinai Hospital, New York City)
}

(Received for publication April 1, 1941)

In a previous paper (1) we reported the results of determinations of total magnesium and ultrafiltrable magnesium in the serum of patients with hyperthyroidism. These findings were contrasted with those obtained in normal individuals, patients with autonomic imbalance, and patients with various types of muscular dystrophy. It was demonstrated that in normal individuals the percentage of the total serum magnesium which is non-diffusible did not exceed 22.1 per cent, with an average of 14.5 per cent, although Watchorn and McCance (2) report that, normally, approximately 25 per cent of the total serum magnesium is bound. The results obtained in patients with autonomic imbalance and various muscular dystrophies fell quite well within the normal range. In contrast to these groups, the patients with hyperthyroidism showed a very marked increase in the percentage of bound magnesium which varied from 21.5 to 61.6 per cent, with an average of 36.0 per cent. It was further pointed out that, after adequate treatment with iodine, there occurred a drop in the percentage of the nondiffusible magnesium fraction, which finally reached normal levels after subtotal thyroidectomy. No correlation was found between the individual basal metabolic rates and the percentage of bound magnesium. This is perhaps due to the fact that the metabolic rate was determined very shortly after admission to the hospital ward and hence may not represent the true basal rate. The increase in the percentage of non-diffusible magnesium in Graves' disease occurred entirely at the expense of the diffusible fraction, since the total serum magnesium in the patients with hyperthyroidism was approximately the same as that of the normal controls.

In the present paper we are reporting further results of studies of magnesium partition in pa-

\footnotetext{
1 Eugene Meyer Jr. Fellow.
}

tients with hyperthyroidism, as well as in individuals with myxedema. We are also including experimental data on totally thyroidectomized dogs.

\section{METHOD}

The total serum magnesium was determined by the method of Briggs (3). The serum proteins were precipitated with trichloracetic acid. It was found that little, if any, magnesium was carried down with the protein flocculum. To $10 \mathrm{cc}$. of protein-free filtrate were added $1 \mathrm{cc}$. of 20 per cent sodium acetate, 6 to 8 drops of 0.016 per cent bromcresol green, and 1 cc. of 4 per cent ammonium oxalate. The $\mathrm{pH}$ of the solution was adjusted to 5.0 by addition of ammonium hydroxide. The mixture was allowed to stand overnight, and the precipitated calcium oxalate was then separated by centrifugation. To the decanted supernatant fluid and washings were added $1 \mathrm{cc}$. of a 2 per cent potassium dihydrogen phosphate, and $1 \mathrm{cc}$. of concentrated ammonia solution. After the mixture had again been allowed to stand overnight, the precipitate was separated by centrifugation and washed with a solution containing $200 \mathrm{cc}$. of 95 per cent alcohol and $50 \mathrm{cc}$. of concentrated ammonia solution per liter. The precipitated magnesium ammonium phosphate was dried and determined according to the method of Kuttner and Lichtenstein (4) by comparison of the color developed on addition of 7.5 per cent sodium molybdate and 0.2 per cent stannous chloride with that of a standard phosphate stock solution.

For the determination of diffusible magnesium, serum was ultrafiltered through a " 600 " cellophane membrane under a pressure of 80 pounds of nitrogen per square inch. The magnesium content of the ultrafiltrate was determined as described above, except that the protein precipitate with trichloracetic acid was omitted.

\section{RESULTS}

In Table I are presented the data obtained on 50 patients with well-defined hyperthyroidism. In each instance, the diagnosis was confirmed by microscopic study of the excised gland. Of this group of 50 patients, the percentage of bound serum magnesium fell within the normal range level in 6 , while it varied between 20 and 25 per 
TABLE I

Distribution of magnesium in cases of hyperthyroidism and relation to average basal metabolic rate

\begin{tabular}{ccc}
\hline \hline $\begin{array}{c}\text { Percentage of bound } \\
\text { magnesium (Serum) }\end{array}$ & $\begin{array}{c}\text { Number of } \\
\text { patients }\end{array}$ & $\begin{array}{c}\text { Average basal } \\
\text { metabolic rate }\end{array}$ \\
\hline per cent & & \\
20 or less & 6 & +36 \\
20 to 25 & 9 & +43 \\
25 to 30 & 7 & +49 \\
30 to 40 & 18 & +44 \\
40 and over & 10 & +45 \\
\hline
\end{tabular}

cent in an additional 9 instances. These latter results were classified as borderline. In the remaining 35 patients the percentage of non-diffusible magnesium was considerably above the normal level.

We attempted to correlate the duration and severity of the illness with the percentage of bound magnesium. For this purpose the data (Table II) were classified according to three time intervals: (a) 0 to 3 months, (b) 3 to 24 months, and $(c)$ more than 24 months. In general, we find no statistically significant difference in magnesium distribution between classes $(a)$ and $(b)$. However, a comparison of $(b)$ and $(c)$ reveals

TABLE II

Relationship of percentage of bound magnesium* to duration of symptoms and to severity of disease

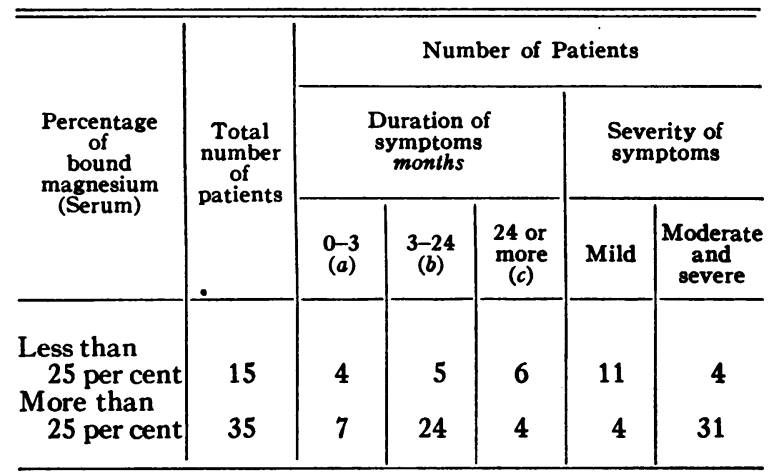

* In order to establish the validity of the correlation inferred from Table II, the data were subjected to contingency analysis. From the data for "low" (less than 3 months) and "average" (3 to 24 months) duration of Graves' disease associated with "normal" (0 to 25 per cent) and "abnormal" (greater than 25 per cent) values for per cent of bound magnesium, Pearson's coefficient of mean square contingency $(C)=0.2$ and $x^{2}=1.67$, which yields a value of $P$ slightly less than 0.20 . This value of $P$ is so large as to afford no evidence of correlation. From the analagous data for "average" and "high" (more than 24 months) duration, $C=0.38, x^{2}=6.71$, and $P=0.01$. In this case, the evidence for correlation is significantly better, the odds being more than 99 to 1 in its favor. FRANKLIN HollaNDER, Ph.D. that the percentage of bound serum magnesium tends to be significantly lower in patients with symptoms of more than 2 years' duration than in the other group (see footnote to Table II). Similarly, an increase in the non-diffusible magnesium is associated with an increase in the severity of the disease-a relation which is directly apparent from the data.

After treatment with iodine there occurs a distinct drop in the percentage of bound serum magnesium, which is lowered further after operation (Table III). In several instances, the non-ultrafiltrable magnesium level in the blood fell to 0.0 per cent. In these instances, the postoperative basal metabolic rate fell to myxedematous levels.

TABLE III

Effect of treatment with iodine and operation on the percentage of bound magnesium

\begin{tabular}{c|c|c|c}
\hline \hline \multirow{2}{*}{$\begin{array}{c}\text { Number } \\
\text { of } \\
\text { cases }\end{array}$} & \multicolumn{2}{|c}{ Average percentage of bound magnesium (serum) } \\
\cline { 2 - 4 } & Control & $\begin{array}{c}\text { After iodine } \\
\text { treatment }\end{array}$ & $\begin{array}{c}\text { After } \\
\text { operation }\end{array}$ \\
\hline $25^{*}$ & 30.6 & 18.9 & \\
$21 \dagger$ & 30.9 & 18.1 & 14.3 \\
15 & 29.5 & 14.5 \\
\hline
\end{tabular}

* In 3 patients there was no appreciable drop in the percentage of bound magnesium after iodine treatment.

t In 3 patients there was no appreciable drop in the percentage of bound magnesium after operation.

In Table IV are presented the data obtained on patients with myxedema. In the 7 instances reported, the percentage of bound serum magnesium was markedly below the normal level, a finding which is the direct antithesis of that observed in Graves' disease. In 3 of the 7 patients, studies were subsequently made after adequate treatment with thyroid extract. In 2 of the 3 instances there occurred an increase in the percentage of bound serum magnesium which approximated the normal values.

We attempted to duplicate these results experimentally. For this purpose total thyroidectomies were performed on 4 dogs. Serum magnesium partition studies were conducted before, and repeatedly after the operation. In each instance, within 17 days to 5 weeks after operation there occurred a profound drop in the percentage of bound magnesium. In dog 181 the bound magnesium could be raised to normal levels by the administration of thyroxin. When the therapy was 
TABLE IV

Serum magnesium studies in patients with myxedema

\begin{tabular}{c|c|c|c|c|}
\hline \hline Name & $\begin{array}{c}\text { Basal } \\
\text { metabolic } \\
\text { rate }\end{array}$ & $\begin{array}{c}\text { Total } \\
\text { magnesium }\end{array}$ & $\begin{array}{c}\text { Ultra- } \\
\text { filtrable } \\
\text { magnesium }\end{array}$ & $\begin{array}{c}\text { Percentage of } \\
\text { magnesium } \\
\text { bound }\end{array}$ \\
\hline & & mgm. per cent & mgm. per cent $\mid$ \\
\hline
\end{tabular}

BEFORE TREATMENT WITH THYROID EXTRACT

\begin{tabular}{l|l|l|l|l}
\hline E. A. & -30 & 2.64 & $2.73^{*}$ & 0 \\
N. & -30 & 1.62 & 1.60 & 0 \\
A. C. & -33 & 2.16 & 2.17 & 0 \\
R. B. & -32 & 2.43 & 2.29 & 5.7 \\
F. & -30 & 2.32 & $2.79^{*}$ & 0 \\
G. G. & -33 & 2.43 & 2.36 & 2.8 \\
G. B. & -22 & 2.60 & 2.61 & 0 \\
\hline
\end{tabular}

AFTER TREATMENT WITH THYROID EXTRACT

\begin{tabular}{l|l|l|l|r} 
E. A. & +2 & 2.31 & 2.02 & 12.5 \\
N. & +7 & 1.66 & 1.49 & 10.2 \\
R. B. & +7 & 2.35 & 2.19 & 5.2 \\
\hline
\end{tabular}

* These values fall below the zero level because of certain technical artefacts which, when corrected, bring the results to the zero level.

discontinued, the non-diffusible magnesium returned to the previous low postoperative level. These changes in bound magnesium could be induced at will by the administration and withdrawal of thyroxin in totally thyroidectomized animals (Table V).

\section{DISCUSSION}

In a large percentage of patients with Graves' disease there occurs a marked increase in the percentage of bound serum magnesium. In patients with well-defined hyperthyroidism in whom the non-diffusible magnesium was normal, certain factors operated which contributed to the normal levels obtained. Many patients with Graves' disease were treated extensively prior to admission to the hospital. Thus, of our group of 15 patients whose bound magnesium was normal or borderline, most had received some medication prior to admission to the hospital ward. It is, of course, difficult to determine the nature of such medication, but it is not inconceivable that iodine, iodides, or iodized salt was part of the therapy employed. Since the use of iodine tends to lower the percentage of bound magnesium, this may have played a part in those instances in which normal values were obtained. It is interesting that patients with unduly prolonged Graves' disease tend to yield normal magnesium partition studies. The reasons for this are at present obscure, but it appears that these changes are mediated through the thyroid and occur only after certain alterations in thyroid function have occurred. This is further supported by the fact that, after thyroidectomy in patients with Graves' disease, the magnesium partition tends to return to a normal pattern. Similarly, in patients with myxedema, or

TABLE $\mathbf{v}$

Data on totally thyroidectomized dogs

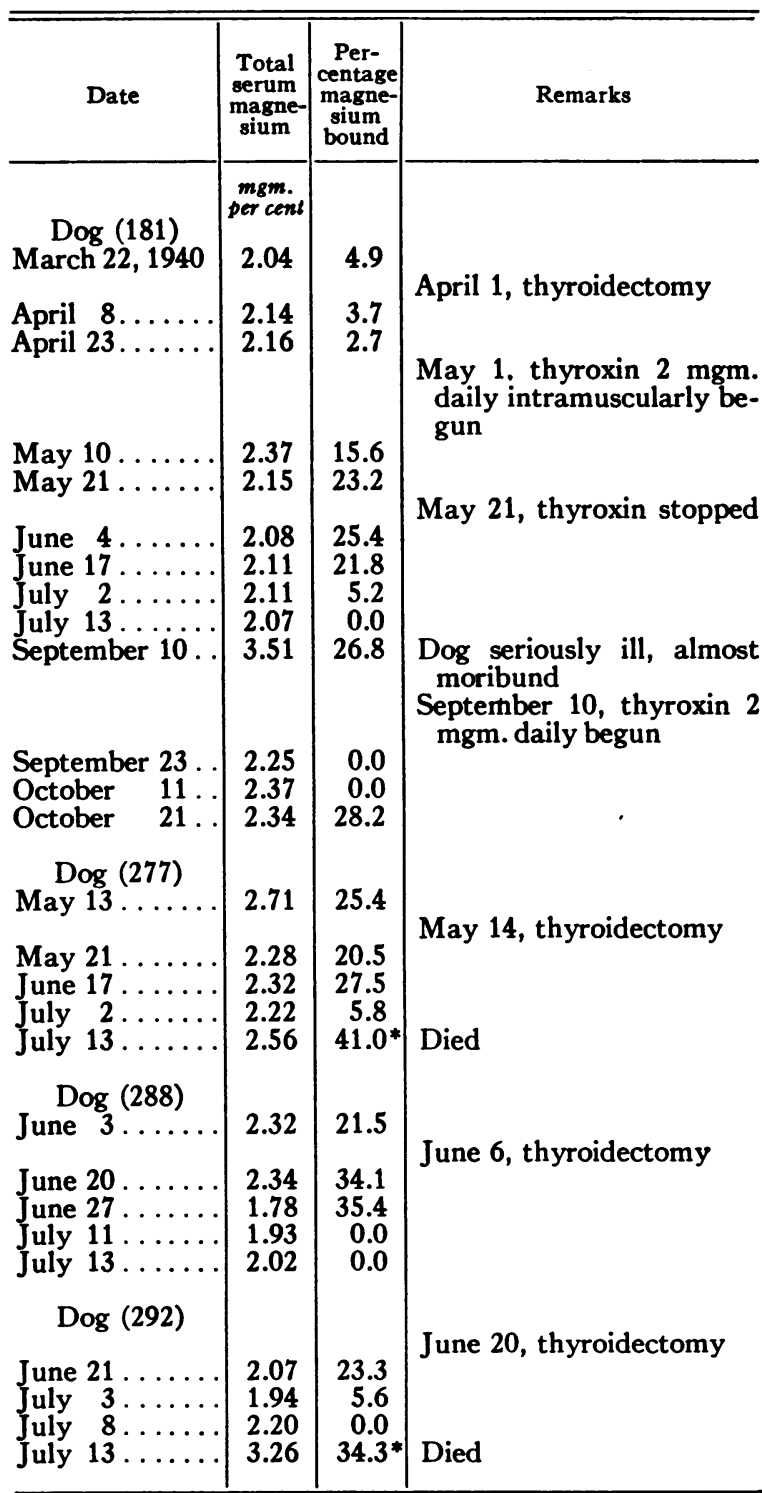

* These determinations were performed on blood drawn a few minutes before the death of the animals, when there apparently occurs a spontaneous preagonal increase in the percentage of bound magnesium. 
in the totally thyroidectomized dog, the non-diffusible serum magnesium can be altered by the administration or withdrawal of thyroid extract. Here, too, a considerable period of time must elapse after administration or cessation of therapy before shift in the ionizable-non-ionizable magnesium ratio occurs. Such magnesium changes do not occur when thyroid extract is administered to dogs with intact thyroids or to normal individuals.

\section{SUMMARY}

1. Serum magnesium partition studies were conducted on 50 patients with proven Graves' disease.

2. In 6 of these patients the percentage of bound serum magnesium fell within the normal range level, that is 20 per cent or less. In 9 additional patients the results were borderline, that is the percentage of bound magnesium varied between 20 and 25 per cent. In 35 , there was a definite increase in the non-diffusible magnesium. The bound fraction in these patients varied between 25 and 61.6 per cent of the total serum magnesium.

3. There is no definite correlation between the percentage of bound serum magnesium and the basal metabolic rate.

4. There is a definite relationship between the duration of the illness and the magnesium partition. Thus, in patients with symptoms of Graves' disease of more than 2 years, the non-diffusible fraction frequently tends to approximate normal levels.
5. After adequate treatment with iodine there occurs a marked drop in the percentage of bound serum magnesium, which is further lowered after subtotal thyroidectomy.

6. In patients with myxedema, as well as in totally thyroidectomized dogs, the non-diffusible serum magnesium fraction is extremely low and frequently is 0 per cent. This is the direct antithesis of the results obtained in Graves' disease.

7. After administration of thyroid extract or thyroxin to the myxedematous patients, and to the thyroidectomized dogs, the percentage of bound serum magnesium returns to approximately normal levels.

8. The increase or decrease of the percentage of bound magnesium occurs at the expense of the ionizable fraction, since the total serum magnesium remains unaltered.

\section{BIBLIOGRAPHY}

1. Soffer, L. J., and others, Ultrafiltrable magnesium in hyperthyroidism. J. Clin. Invest., 1939, 18, 597.

2. Watchorn, E., and McCance, R. A., Inorganic constituents of cerebrospinal fluid; ultrafiltration of calcium and magnesium from human sera. Biochem. J., 1932, 26, 54.

3. Briggs, A. P., Colorimetric method for determination of small amounts of magnesium. J. Biol. Chem., 1922, 52, 349.

4. Kuttner, T., and Lichtenstein, L., Micro colorimetric studies. II. Estimation of phosphorous: molybdic acid-stannous chloride reagent. J. Biol. Chem., 1930, 86, 671. 